\title{
Analysis of the presence of sustainability in Higher Education Degrees of the Spanish university system
}

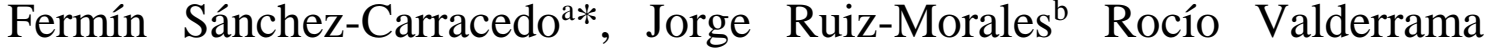 \\ Hernández ${ }^{\mathrm{c}}$, José Manuel Muñoz ${ }^{\mathrm{d}}$, Antonio Gomera ${ }^{\mathrm{e}}$
}

${ }^{a}$ University Research Institute for Sustainability Science And Technology, Universitat Politècnica de Catalunya-BarcelonaTech, Barcelona, Spain, 0000-0001-6954-7643;

${ }^{b}$ Didáctica de las Ciencias Experimentales y Sociales, Universidad de Sevilla, Sevilla, Spain, 0000-0002-6081-9363; 'Teoría e Historia de la Educación y Pedagogía Social, Universidad de Sevilla, Sevilla, Spain, 0000-0002-6065-1425; ${ }^{d}$ Teoría e Historia de la Educación, Universidad de Salamanca, Salamanca, Spain, 0000-0002-4688-6420; ${ }^{e}$ Environmental Protection Service, Universidad de Córdoba, Córdoba, Spain, 00000003-0603-3017.

\begin{abstract}
This paper analyzes the extent to which sustainability is present in the curricula of the sixteen Education Degree programs belonging to the EDINSOST project: Six Early Childhood Education Degrees, seven Primary Education Degrees, two Pedagogy Degrees and one Social Education Degree. The results obtained suggest that sustainability is present in all Degrees, but not uniformly so. A great disparity is observed in the number of subjects that develop sustainability, with an average of 22.63 subjects per Degree. The competency most present is the 'Application of ethical principles related to the values of sustainability in personal and professional behaviors', while the least present is 'Sustainable use of resources and prevention of negative impacts on the natural and social environment'. Sustainability is not developed uniformly in the different universities either. Three universities (UAM, UCA and UIC) develop sustainability competencies at $100 \%$, while others such as the USAL do so at only $50 \%$.
\end{abstract}

This is an Accepted Manuscript of an article published by Taylor \& Francis Group in Studies in Higher Education on 20 Jun 2019, available online at: http://www.tandfonline.com/10.1080/03075079.2019.1630811 
Keywords: Sustainability, competencies in sustainability, sustainable development goals, sustainability competency map, Education for sustainable development, Higher Education Degrees.

\section{Introduction}

The 2030 Agenda of the United Nations includes seventeen Sustainable Development Goals (SDG). The SDGs are a priority to be implemented by different governments, civil society and business sectors over the next twelve years. Education is one of the key elements required to make Sustainable Development part of the daily life of people, as recognized by UNESCO (2017). It is therefore necessary to train professionals capable of acting as agents of change and transformation in socio-environmental reality. In the context of the European Higher Education Area, since the beginning of the 21st century competency-based education has risen remarkably in universities (Cotton et al. 2009; Sales de Aguiar and Paterson 2017), which has become a fundamental means of professional training for achieving this objective.

Different strategies have been used to include Sustainability ${ }^{1}$ in the curricula. In some cases, sustainability has been distributed among different technical subjects ${ }^{2}$. Other Degree programs have decided to incorporate specific subjects related to socioenvironmental education. In Spanish universities, in 2005 the CRUE $^{3}$ Sectorial Sustainability Commission published the document 'Guidelines for the Introduction of Sustainability in the Curriculum', which was updated in 2011 and expanded in 2012

\footnotetext{
${ }^{1}$ Although the concept of Sustainable Development is broader than the concept of sustainability, from now on we will use the word sustainability for coherence with the rest of the documentation referenced in the text.

${ }^{2} \mathrm{~A}$ subject is a module of knowledge that has a certain number of credits and that is part of an academic curriculum.

${ }^{3}$ CRUE refers to the Conference of Presidents of Spanish Universities
} 
(CRUE 2012). The document defines four competencies related to sustainability that should be included in all university curricula:

- SUS1: Critical contextualization of knowledge by establishing interrelations with social, economic, environmental, local and/or global problems.

- SUS2: Sustainable use of resources and prevention of negative impacts on the natural and social environment.

- SUS3: Participation in community processes that promote sustainability.

- SUS4: Application of ethical principles related to the values of sustainability in personal and professional behavior.

The inclusion of sustainability in university curricula is conditioned by some important factors, such as teacher training and teachers' conceptions of sustainability. Shephard and Furnari (2013) conclude that in order to define the training process necessary to achieve the desirable level of training, it is essential to identify which ideas exert the most influence on teachers in their teaching practice.

The university is the ideal place to develop the culture of sustainability. For this reason, the objective of the EDINSOST project is to contribute to the training of graduates capable of spearheading the search for solutions to the challenges facing our society by integrating sustainability training into the Spanish University System. The project involves 55 researchers who study 13 Degrees from 10 Spanish universities:

- Five Engineering Degrees and three Degrees related to the three dimensions of sustainability, given their great impact on the short-term challenges confronting society.

- Bachelor and Master Degrees of five Education Degrees, since graduates from these programs will be the future teachers of new generations of citizens. 
Objective $\mathrm{N}^{\mathrm{o}} 1$ of EDINSOST consists of designing a Sustainability Competency Map for each Degree as well as analyzing the curriculum of the Degrees involved in the project. Given that sustainability is a transversal competency, just two sustainability competency maps have been designed rather than a single map drawn up according to Degrees: a map for Engineering Degrees (Sánchez-Carracedo et al. 2018) and another map for Education Degrees (Albareda-Tiana et al. 2019).

The work presented in this paper forms part of Objective $\mathrm{N}^{\circ} 1$ of EDINSOST. The other objectives of the project are as follows: to validate the most appropriate didactic strategies for developing sustainability (Objective $\mathrm{N}^{\mathrm{o}} 2$ ); to conduct a diagnosis of the competence in sustainability of the faculty (Objective $\mathrm{N}^{\circ} 3$ ) and the students (Objective $\mathrm{N}^{\mathrm{o}} 4$ ), in order to propose a set of training actions aimed at improving the didactic competency of faculty (Segalàs et al. 2018).

The aim of this paper is to analyze the presence of sustainability in the university curriculum of the EDINSOST Higher-Education-Degree programs. The Education Degrees of seven Spanish universities are analyzed. We consider these Degrees as a representative sample that enables us to build up an overall picture of the presence of sustainability in the Education Degree programs of Spanish Universities.

The rest of the paper is organized as follows: Section 2 presents the methodology and tools used in this study to analyze the presence of sustainability in the Degrees under study. The Degrees and universities participating in the study are also defined in Section 2. The results are presented in Section 3 and discussed in Section 4. Finally, Section 5 concludes the paper.

\section{Materials and methods}

The present work seeks to answer the following research questions: 
- Q1: To what extent do the analyzed Degrees consider the competencies in sustainability established by the CRUE?

- Q2: What competencies are more present (strengths) and less present (weaknesses) in the Degrees?

- Q3: Are there differences in the presence of sustainability competencies in the different Degree programs?

To answer these questions, an investigation has been designed to analyze the presence of the competencies in sustainability defined by the CRUE (2012) in the curricula. This work is exploratory and not exhaustive, since only a small set of Degrees is analyzed. The purpose of this work is not to generalize the obtained results, but to acquire relevant information regarding the extent to which sustainability competencies are being developed in a set of Degrees at this particular time. Although the results are not generalizable, they may help to determine how Education Degrees of Spanish universities develop these competencies.

The research has been carried out in seven Spanish universities participating in the EDINSOST Project: the Autonomous University of Madrid (UAM), the University of Cádiz (UCA), the University of Córdoba (UCO), the International University of Catalonia (UIC), the University of Seville (US), the University of Salamanca (USAL), and the Camilo José Cela University (UCJC). The Degrees analyzed are those in Early Childhood Education (6 universities), Primary Education (7 universities), Social Education (1 university) and Pedagogy ( 2 universities). The results obtained for the Early Childhood and Primary Education Degrees are considered relevant due to the high number of Degrees analyzed (13). The results from Pedagogy and Social Education Degree programs are presented solely for purposes of information. 
The instrument used for data collection is the sustainability competency map of Education Degrees (Albareda-Tiana et al. 2019). This map specifies the four sustainability competencies defined by the CRUE in the form of Competency Units (CU), which define the main aspects of each competency. Each $\mathrm{CU}$ is defined by Learning Outcomes (LO) classified into three domain levels. A simplified version of the Miller Pyramid (Miller 1990) has been used as taxonomy. In order to reduce the taxonomy to only three domain levels, the two highest levels ('Demonstrate' and 'Do') have been combined into a single level, so that the domain levels used in the map are as follows: 'Know', 'Know How' and 'Demonstrate + Do'. Table 1 presents a reduced version of the Sustainability Competency Map in which only competencies and CUs are included. The complete Sustainability Competency Map can be consulted in the Appendix 1.

Table 1. Sustainability Competency Map of Higher Education Degrees (simplified)

\section{Competency}

SUS1- Critical contextualization of knowledge by establishing interrelations with social, economic, environmental, local and/or global problems.

SUS2- Sustainable use of resources and prevention of negative impacts on the natural and social environment.

SUS3- Participation in community processes that promote sustainability.

SUS4- Application of ethical principles related to the values of sustainability in personal and

\section{Competency Unit}

1.1 Understands the functioning of natural, social and economic systems, as well as their interrelations and problems, both at a local and global level.

1.2 Possesses critical thinking and creativity, taking advantage of the different opportunities presented (ICT, strategic plans, regulations, etc.) in the planning of a sustainable future.

2.1. Designs and develops actions, making decisions that take into account the environmental, economic, social, cultural and educational impacts so as to improve sustainability.

3.1 Promotes and participates in community activities that encourage sustainability.

4.1. Is consistent in actions respecting and valuing (biological, social and cultural) diversity and 
professional behavior. committed to improving sustainability.

4.2. Promotes education in values oriented to the formation of responsible, active and democratic citizens.

This research is of a quantitative nature: the objective is to determine whether or not a certain competency is developed in a certain Degree rather than the extent to which it is developed, or whether or not it is developed correctly.

The procedure used in this research consists in checking the presence of each LO in the curricula of the Degrees under study. The teaching guides for all the subjects of each Degree have been analyzed in order to identify which subjects develop each LO in the Sustainability Competency Map. In case of doubt, the faculty responsible for the subject has been consulted. With this methodology, we have identified which subjects develop each domain level for each CU.

\section{Results}

The Degrees analyzed in this paper are as follows: the Bachelor Degree in Early Childhood Education (ECE), the Bachelor Degree in Primary Education (PE), the Bachelor Degree in Pedagogy (P), and the Bachelor Degree in Social Education (SE). For each CU, Table 2 shows the number of subjects developing each level $(\mathrm{L} 1=$ Know, L2 $=$ Know How, and L3 = Demonstrate+Do). The cases in which no subject develops at least one LO of a certain domain level (the content of the cell is 0 ) are shaded. This information is useful to determine which $\mathrm{CU}$ domain levels are not developed in each Degree.

Table 2. Number of subjects developing each CU domain-level and Degree. 


\begin{tabular}{|c|c|c|c|c|c|c|c|c|c|c|c|c|c|c|c|c|c|c|c|c|c|}
\hline \multirow{3}{*}{ 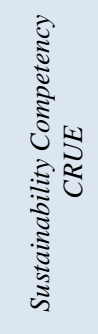 } & \multirow{3}{*}{ 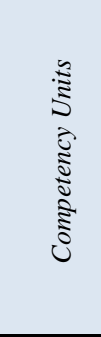 } & \multirow{3}{*}{ 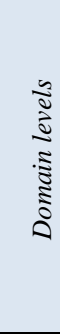 } & \multicolumn{6}{|c|}{$\begin{array}{c}\text { Bachelor Degree in } \\
\text { Early Childhood } \\
\text { Education }\end{array}$} & \multicolumn{7}{|c|}{$\begin{array}{c}\text { Bachelor Degree in Primary } \\
\text { Education }\end{array}$} & \multicolumn{2}{|c|}{$\begin{array}{l}\text { Bachelor } \\
\text { Degree in } \\
\text { Pedagogy }\end{array}$} & \multirow[t]{2}{*}{$\begin{array}{l}\text { Bachelor } \\
\text { Degree in } \\
\text { Social } \\
\text { Education }\end{array}$} & \multicolumn{3}{|c|}{$\begin{array}{c}\text { \% No Presence of Learning } \\
\text { Outcomes }\end{array}$} \\
\hline & & & \multicolumn{18}{|c|}{ Universities participants in Higher Education Degrees } & \\
\hline & & & 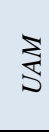 & క & @ & $\stackrel{৩}{\Im}$ & 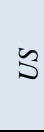 & 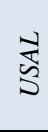 & $\sum$ & ঠু & U & @ & 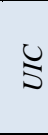 & 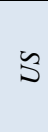 & 㐫 & 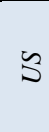 & 㐫 & 苮 & 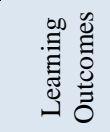 & $己$ & छें \\
\hline \multirow{6}{*}{ SUS1 } & \multirow{6}{*}{ CU 1.2} & L1 & 1 & 7 & 3 & 8 & 1 & 5 & 2 & 6 & 5 & 0 & 8 & 5 & 13 & 10 & 15 & 3 & $6,25 \%$ & \multirow{4}{*}{$16,67 \%$} & \multirow{6}{*}{$16,67 \%$} \\
\hline & & L2 & 1 & 7 & 10 & 5 & 1 & 0 & 2 & 6 & 4 & 8 & 6 & 0 & 2 & 4 & 4 & 5 & $12,50 \%$ & & \\
\hline & & L3 & 1 & 5 & 0 & 3 & 1 & 2 & 2 & 6 & 0 & 0 & 6 & 0 & 2 & 1 & 0 & 3 & $31,25 \%$ & & \\
\hline & & L1 & 4 & 17 & 10 & 16 & 4 & 1 & 8 & 18 & 3 & 22 & 12 & 0 & 2 & 2 & 1 & 1 & $6,25 \%$ & & \\
\hline & & L2 & 4 & 17 & 4 & 12 & 1 & 1 & 6 & 16 & 2 & 0 & 10 & 0 & 2 & 1 & 0 & 1 & $18,75 \%$ & $16,67 \%$ & \\
\hline & & L3 & 4 & 13 & 16 & 9 & 0 & 1 & 6 & 16 & 5 & 4 & 8 & 0 & 1 & 1 & 0 & 0 & $25,00 \%$ & & \\
\hline \multirow{3}{*}{ SUS2 } & \multirow{3}{*}{ CU 2.1} & $\mathrm{~L} 1$ & 1 & 13 & 4 & 17 & 4 & 0 & 2 & 14 & 2 & 3 & 13 & 0 & 2 & 4 & 4 & 0 & $18,75 \%$ & \multirow{3}{*}{$35,42 \%$} & \multirow{3}{*}{$35,42 \%$} \\
\hline & & L2 & 1 & 12 & 0 & 10 & 0 & 0 & 3 & 12 & 2 & 0 & 10 & 0 & 0 & 2 & 1 & 1 & $37,50 \%$ & & \\
\hline & & L3 & 1 & 9 & 0 & 7 & 0 & 0 & 3 & 12 & 0 & 0 & 9 & 0 & 0 & 1 & 0 & 2 & $50,00 \%$ & & \\
\hline \multirow{3}{*}{ SUS3 } & \multirow{3}{*}{ CU 3,1 } & L1 & 4 & 5 & 2 & 8 & 1 & 0 & 7 & 7 & 2 & 25 & 6 & 3 & 0 & 4 & 1 & 2 & $12,50 \%$ & \multirow{3}{*}{$20,83 \%$} & \multirow{3}{*}{$20,83 \%$} \\
\hline & & L2 & 4 & 5 & 11 & 4 & 3 & 0 & 9 & 7 & 0 & 6 & 2 & 1 & 0 & 3 & 1 & 8 & $18,75 \%$ & & \\
\hline & & L3 & 4 & 4 & 6 & 4 & 0 & 0 & 9 & 7 & 0 & 16 & 2 & 0 & 0 & 1 & 1 & 3 & $31,25 \%$ & & \\
\hline \multirow{6}{*}{ SUS4 } & \multirow{3}{*}{ CU 4.1} & L1 & 5 & 17 & 5 & 18 & 0 & 2 & 14 & 18 & 4 & 0 & 14 & 3 & 19 & 3 & 3 & 5 & $12,50 \%$ & & \multirow{6}{*}{$15,63 \%$} \\
\hline & & L2 & 4 & 15 & 15 & 16 & 2 & 1 & 9 & 15 & 3 & 5 & 12 & 0 & 3 & 1 & 6 & 0 & $12,50 \%$ & $14,58 \%$ & \\
\hline & & L3 & 4 & 12 & 12 & 9 & 0 & 1 & 6 & 15 & 3 & 21 & 10 & 0 & 0 & 1 & 4 & 4 & $18,75 \%$ & \multirow{4}{*}{$16,67 \%$} & \\
\hline & \multirow{3}{*}{ CU 4.2} & L1 & 7 & 15 & 0 & 20 & 14 & 8 & 14 & 20 & 4 & 15 & 16 & 0 & 10 & 1 & 0 & 4 & $18,75 \%$ & & \\
\hline & & L2 & 7 & 14 & 0 & 17 & 2 & 1 & 17 & 17 & 3 & 13 & 13 & 0 & 0 & 1 & 0 & 2 & $25,00 \%$ & & \\
\hline & & L3 & 5 & 11 & 0 & 14 & 3 & 1 & 14 & 17 & 3 & 18 & 11 & 2 & 1 & 1 & 1 & 12 & $6,25 \%$ & & \\
\hline $\begin{array}{l}\text { Subject } \\
\text { Sustain }\end{array}$ & $\begin{array}{l}\text { developi } \\
\text { bility }\end{array}$ & & 8 & 26 & 36 & 20 & 19 & 20 & 19 & 30 & 11 & 45 & 19 & 9 & 28 & 11 & 27 & 27 & & & \\
\hline & Compu & sory & 30 & 30 & 30 & 31 & 28 & 30 & 32 & 30 & 34 & 30 & 32 & 28 & 31 & 25 & 32 & 31 & & & \\
\hline $\begin{array}{c}\text { Total } \\
\text { subjects }\end{array}$ & Elect & & 24 & 16 & 15 & 20 & 14 & 15 & 31 & 24 & 12 & 29 & 26 & 19 & 15 & 20 & 21 & 15 & & & \\
\hline & Othe & & & & & & & & & & 53 & & & & & & & & & & \\
\hline
\end{tabular}

The three columns on the right of Table 2 provide information on the percentage of Degrees that do not develop any LO in any domain level of a given CU. For example, $6.25 \%$ of the first row in the column 'Learning Outcomes' indicates that $6.25 \%$ of the Degrees do not develop any LO at level L1 (Knowledge) of the CU1.1 in any subject. This case is the PE Degree at the UCO, the only Degree that presents a 0 in that row. This information can be extrapolated to yield the percentage of Degrees in which no domain level of any $\mathrm{CU}$ is developed (column $\mathrm{CU}$ ), or the percentage of Degrees in which no domain level of any competency is developed (column Comp.). The last rows 
show the number of subjects that implement sustainability in each Degree (subjects developing sustainability) and the number of total subjects in each Degree.

We have analyzed the number of subjects that develop sustainability in each Degree at each university, taking all the data into consideration as well as regarding as outliers the Degrees that have fewer than 10 subjects (ECE-UAM and PE-US) or more than 30 (ECE-UCO and PE-UCO). The results are similar in both cases, except for a slight increase in the standard deviation. Therefore, in this work the results are presented without eliminating any possible outlier. Figure 1 shows this data.

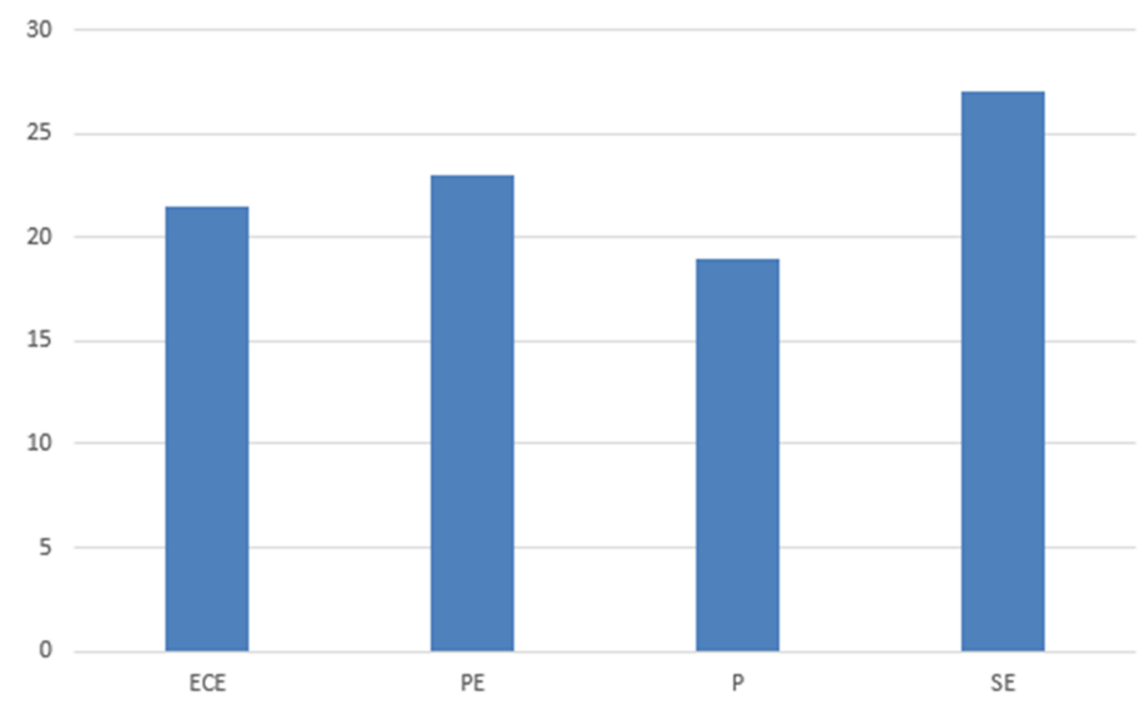

Figure 1. Average of subjects that develop sustainability according to Degree

Figure 2 shows the average number of subjects per Degree that develop sustainability in each university. 


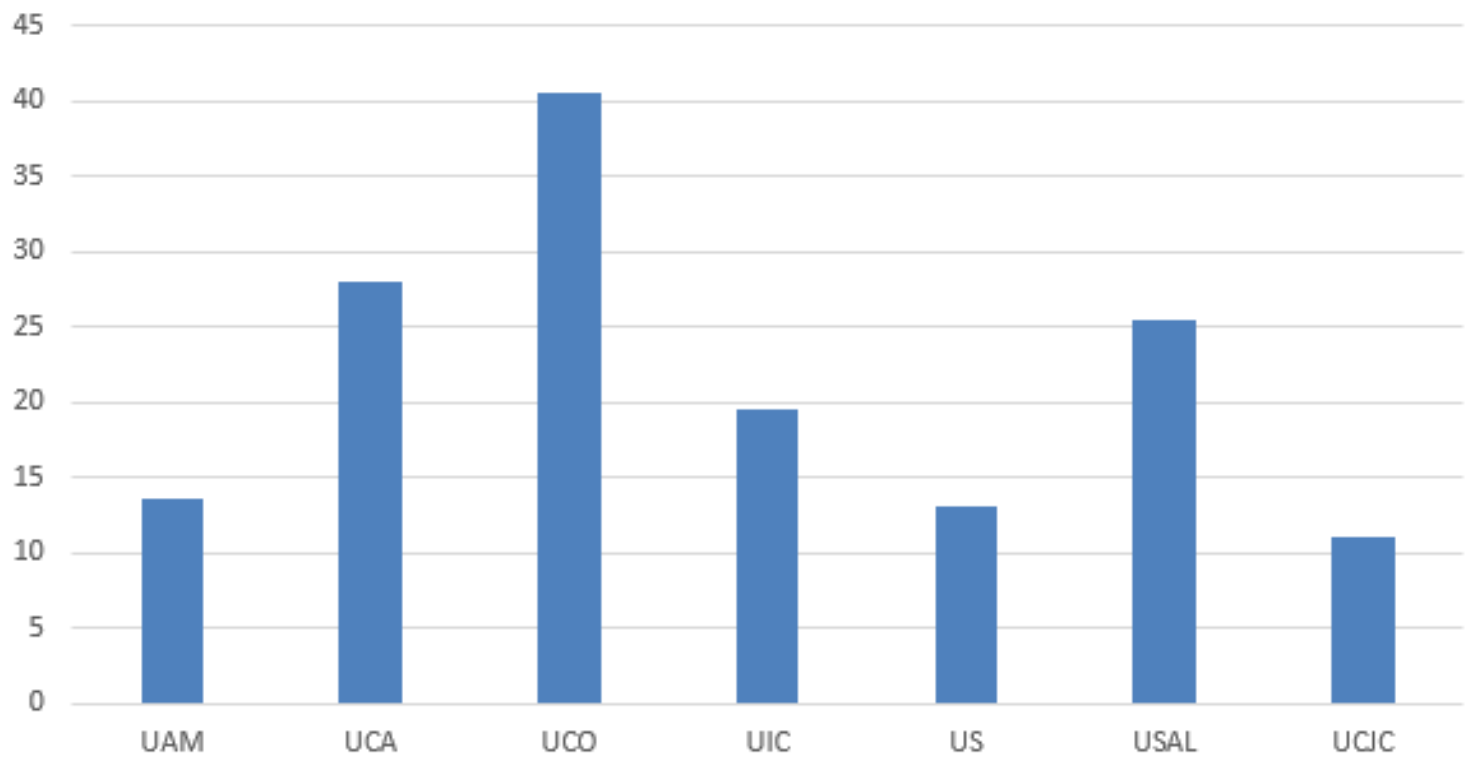

Figure 2. Average number of subjects per Degree that develop sustainability in each university

From the results shown in Table 2, we have analyzed which competencies are developed in each Degree and at which domain level. To this end, we assume that a competency is developed if any LO of the competency is developed in any subject (regardless of the domain level and the number of subjects that develops it). This is equivalent to a new table in which each cell containing a number greater than zero is replaced by 1 , while zeros are maintained (identifying competencies that are not developed at some level).

To determine the extent to which each competency is developed in each Degree and university, we have assigned a fractional value of between 0 and 1 according to the following criteria:

- If the competency has only one CU (SUS2 and SUS3), it is developed at 100\%

(value 1) when subjects develop it at the three domain levels. If subjects develop LOs at only two domain levels, we assume that the competency develops at 
$66.6 \%$ (value $2 / 3$ ). If subjects develop a single domain level, we assume that the competency develops at 33\% (value $1 / 3$ ). Finally, if none LO of any of the domain levels is developed, then the competency develops at $0 \%$ (value 0 ). For example, in Table 2, the UAM would have a value 1 assigned to each competency, because all of them are developed at the three domain levels in at least one subject. However, in the case of the ECE-UCO, the value assigned to SUS2 would be $1 / 3$, since only one of the three domain levels is developed in any subject.

- If the competency has two CUs (SUS1 and SUS4), the possible values to describe the development of each competency are, from highest to lowest, 1, 5/6, $2 / 3,1 / 2,1 / 3$ and 0 , since six cells contain LOs related to the competency, and therefore subjects in the six cells (value 1) or in fewer cells can be found. The development of the competency, in this case, is the number of cells containing subjects that develop some LO divided by 6 . For example, in the case of the ECE-UCO, the value assigned to SUS1 would be 5/6, since one of the domain levels of SUS1 (the L3 of the CU1.1) is not developed at any subject, and would be $1 / 2$ for SUS4 (3 domain levels are not developed in any subject).

The objective of this study is not to analyze the extent to which each competency is developed, but to determine the level of presence of the competency in each Degree. For this reason, we have not analyzed how many LOs are developed in each cell, nor how many subjects each of the learning outcomes develop, nor how many hours each does subject devote to each LO.

Figure 3 compares the presence of the sustainability competencies obtained for the four Degrees studied. The results of the P and SE Degrees are purely indicative. On 
the other hand, we consider the results of the ECE and PE Degrees to be relevant, because data from 6 and 7 universities respectively have been considered.

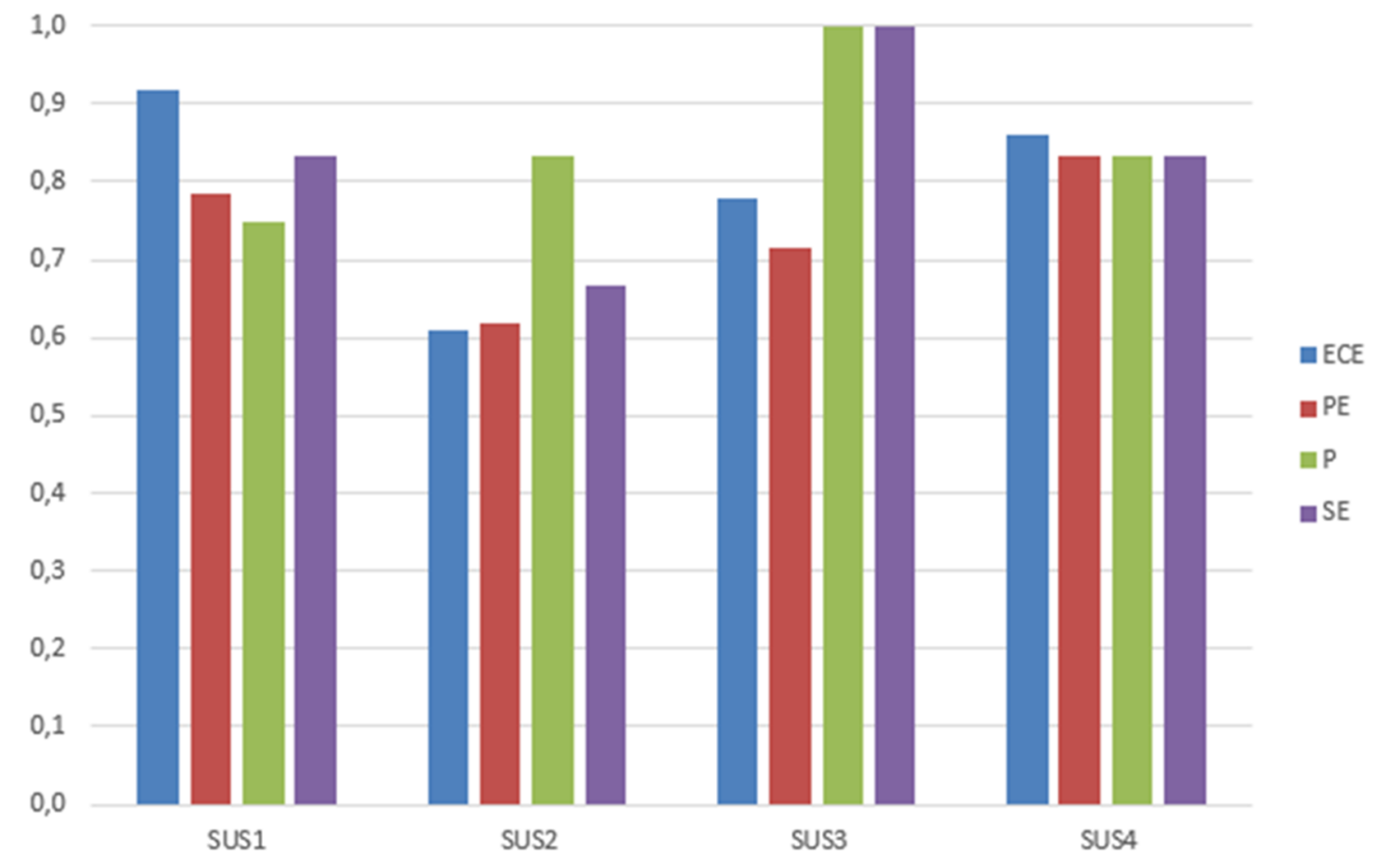

Figure 3. Presence of the sustainability competencies in each Degree

Figure 3 should be interpreted as follows: Each bar identifies the percentage of Degrees in which each competency is developed. For example, the bar on the left of SUS1 (corresponding to the ECE Degree) indicates that approximately $90 \%$ of the cells of all ECE Degrees studied contain LOs of SUS1. Since SUS1 has two CUs, and therefore represents 6 cells in the map, and given that we have studied 6 ECE Degrees (36 cells in total), then 33 of the 36 cells $(91.66 \%$ ) have some subject in which some LOs are developed. The presence of a given competency is different for each Degree (see the four bars together for each competency), with the exception of SUS4, which is more homogeneous. For each Degree, some competencies are more present than others (bars of the same color-position). 
Figures 4 and 5 show the data presented in Figure 3 disaggregated by Degrees and by universities. Figure 4 shows the presence of each competency in each university in the ECE Degree, while Figure 5 shows the same data for the PE Degree. The presence of SUS2 and SUS3 in ECE Degree of the USAL is '0', so no bar is presented for the USAL in Figure 4.

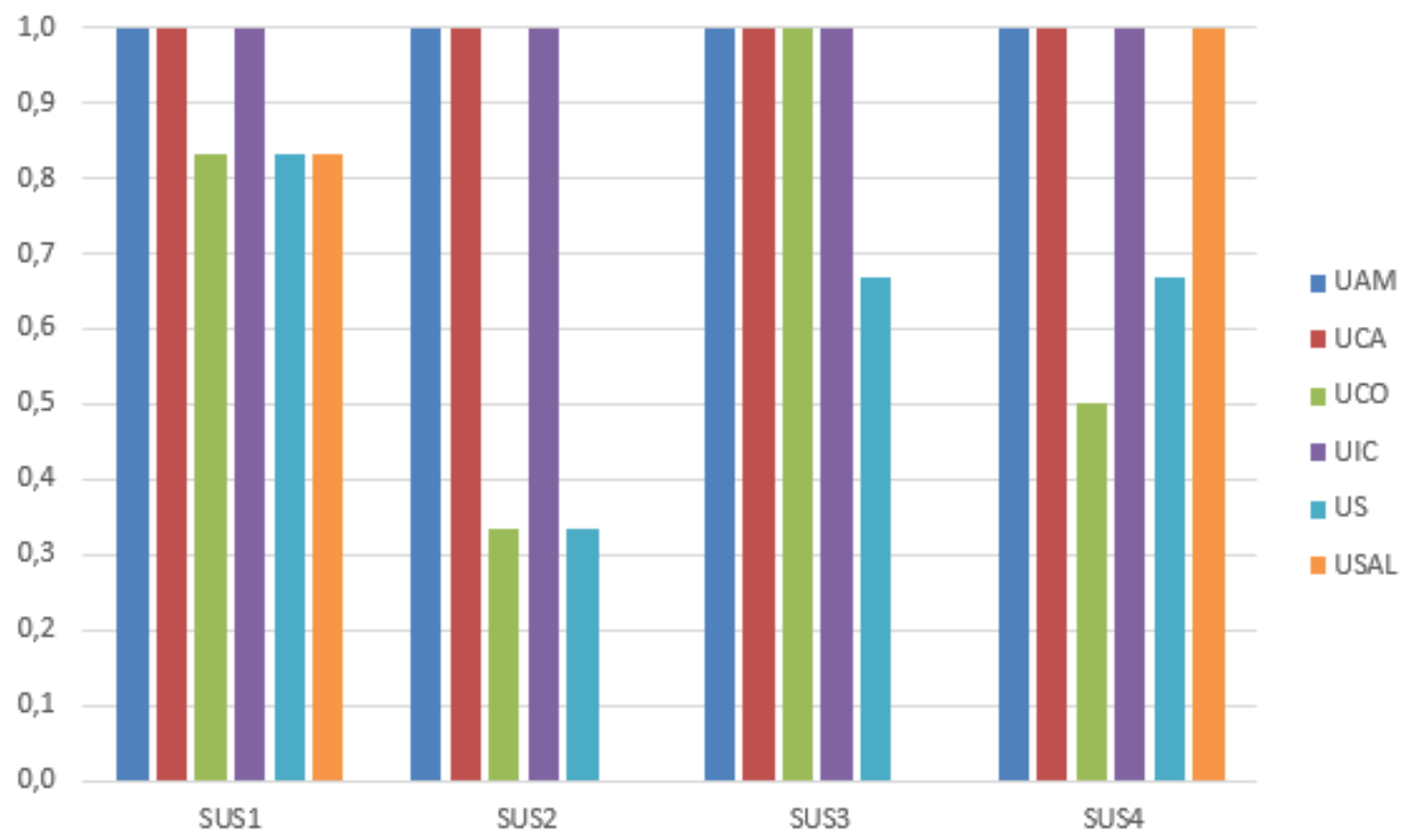

Figure 4. Presence of the sustainability competencies in the ECE Degree by university

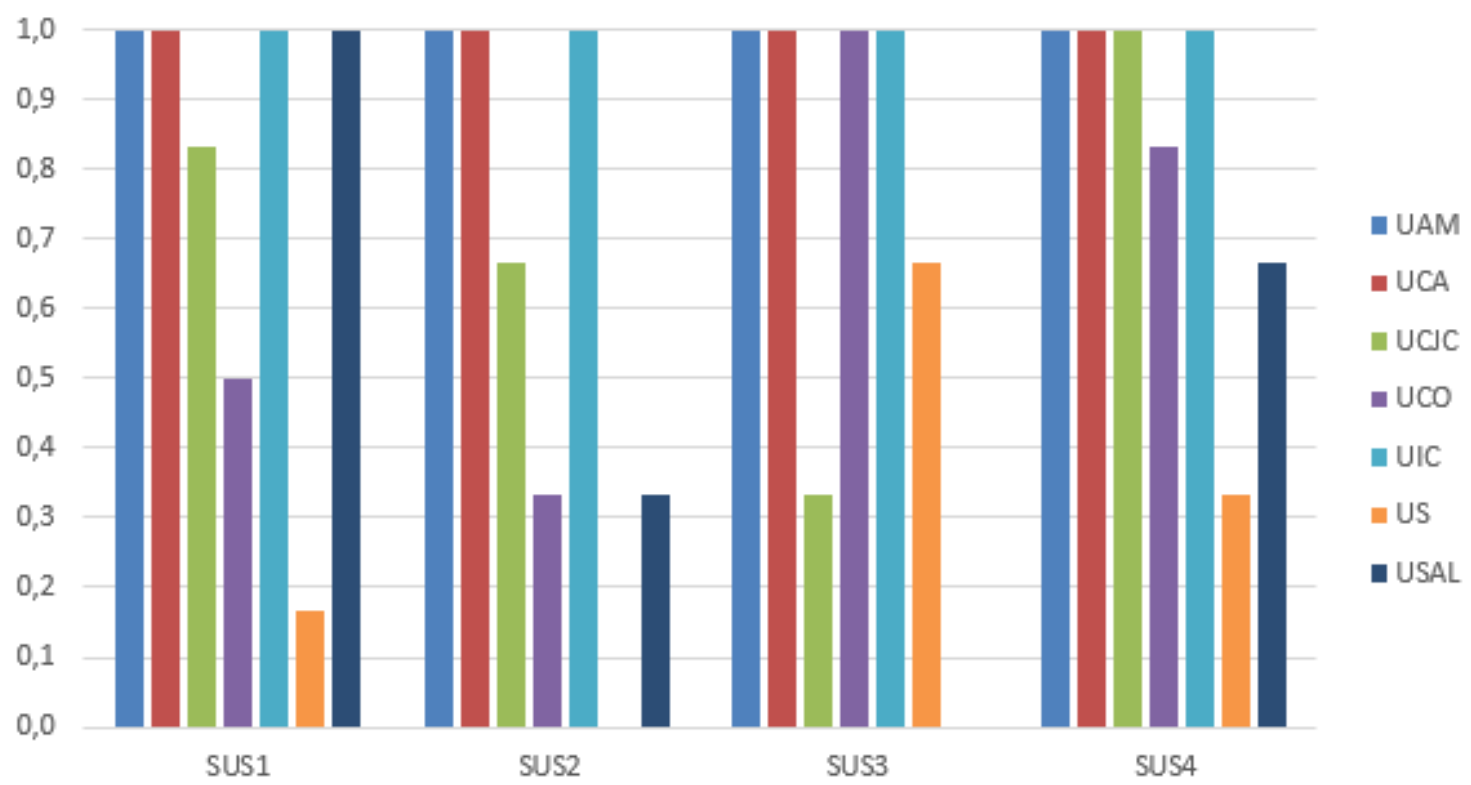


Figure 5. Presence of the sustainability competencies in the PE Degree by university

Figure 6 shows the Sustainability presence for the ECE and PE Degrees in the different universities, considered as the sum of the presence of the four competencies and normalized to 1 . Since each competency can have a presence between 0 and 1 , the presence of the four competencies when considered together is between 0 and 4 . To normalize this result, and make it comparable to the rest of the figures, we have divided this number by 4 , so the range of presence for all competencies is again between 0 and 1. For each university, the bar on the left shows the ECE Degree, and the bar on the right the PE Degree. The UCJC has only one bar because data for ECE Degree are not available.

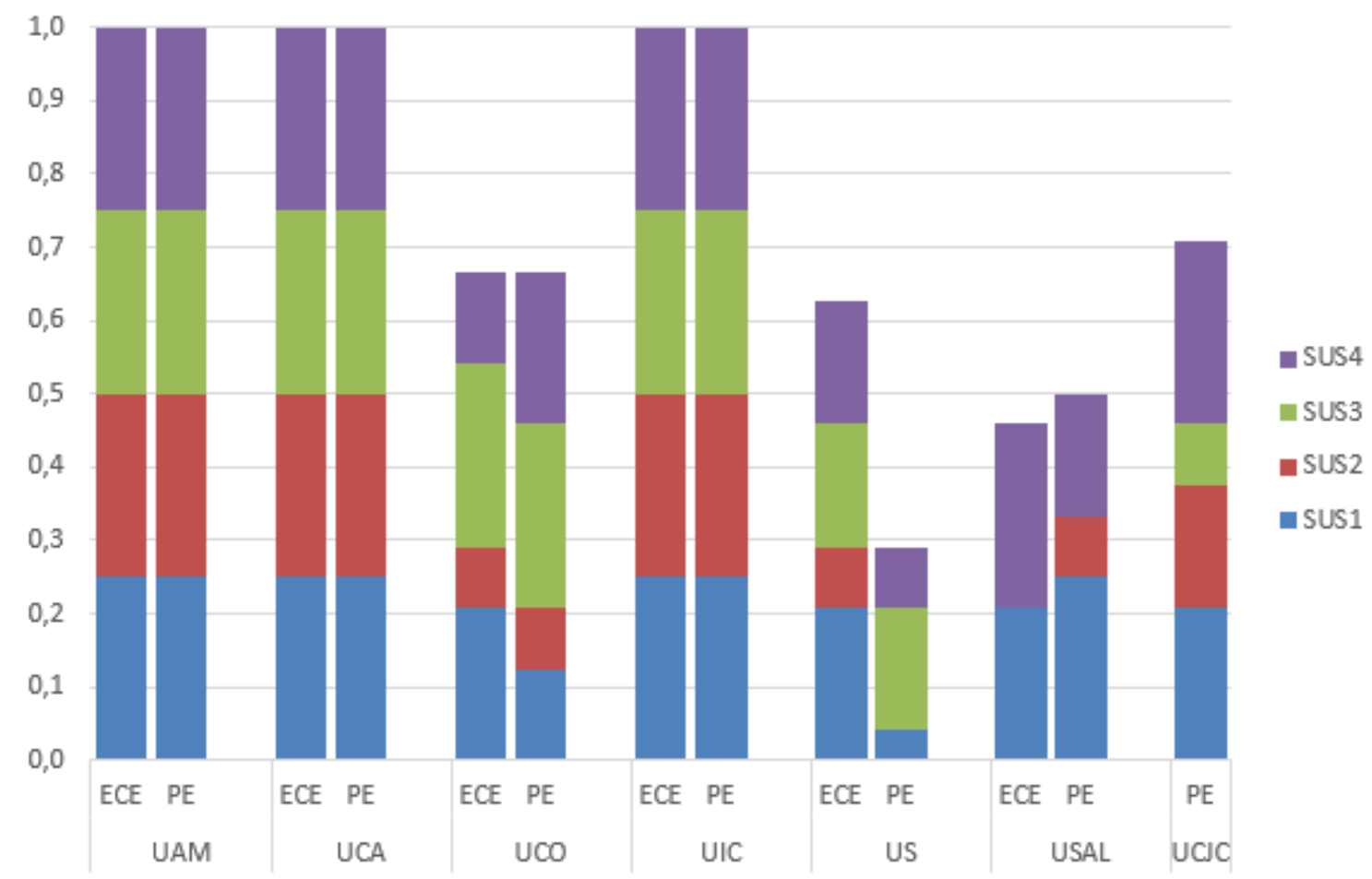

Figure 6. Presence of Sustainability in each university in ECE and PE Degrees 
We have also analyzed which domain levels are developed most for each competency. For the 16 Degrees analyzed, Figure 7 shows the percentage of Degrees in which each of the domain levels of each competency is developed. In general, lower domain levels are developed more frequently than higher levels, and SUS2 is slightly less present than the other competencies. We have observed no significant differences in the results between PE and ECE Degrees, so we have not included these figures.

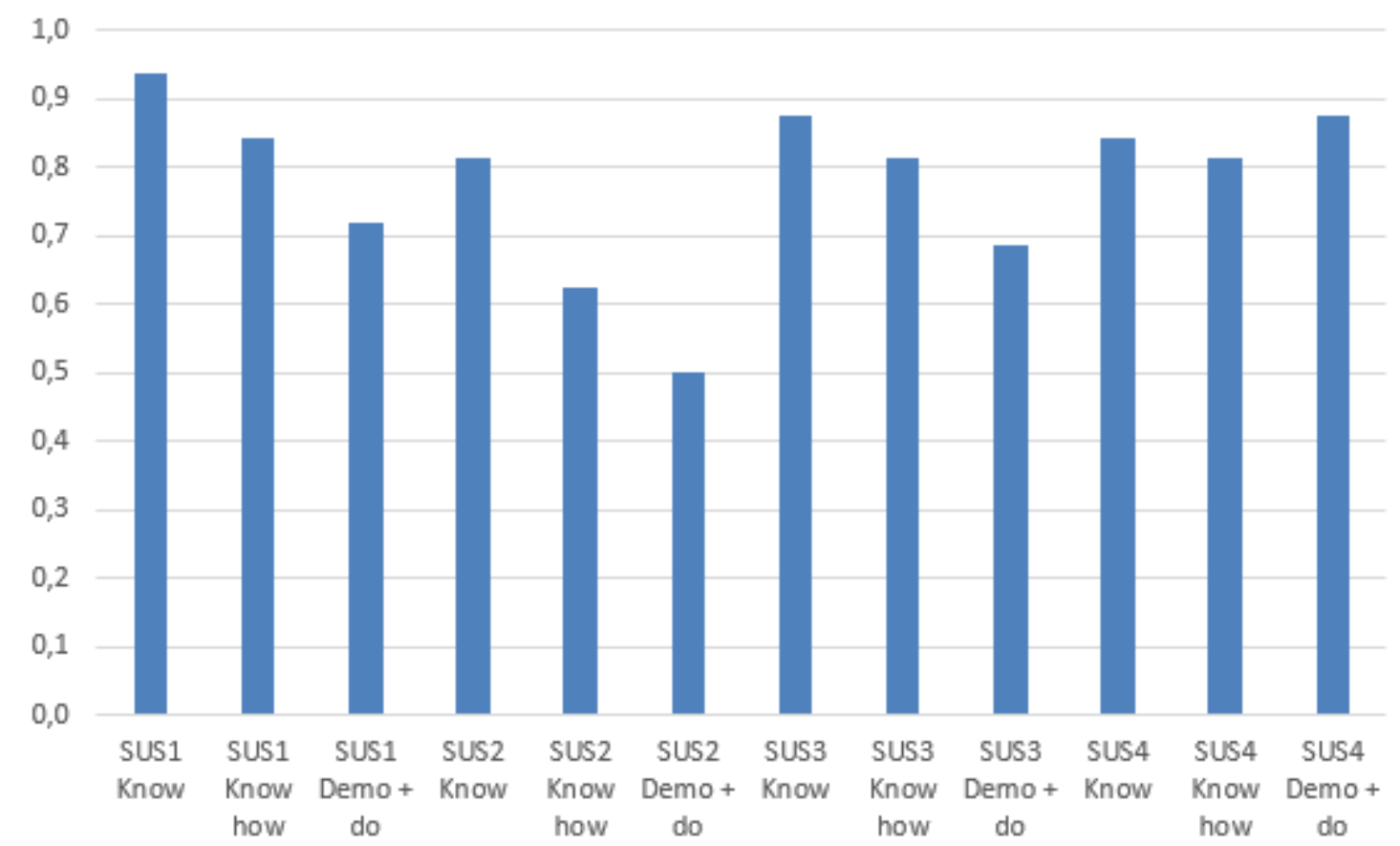

Figure 7. Presence of each domain level for each sustainability competency

Finally, we have studied whether or not a correlation exists between the number of subjects that develop sustainability in each Degree in each university, and the presence of sustainability in the Degree (Figure 6). The correlation can be approximated by a line when the points representing the Degrees claiming to develop all the domain levels of every competency are discarded. This line is represented in Figure 8. The six points that have not been considered are those that appear in the upper part of the figure, without labelling (presence $=1$ ). When these points are taken into account, no correlation is obtained. 


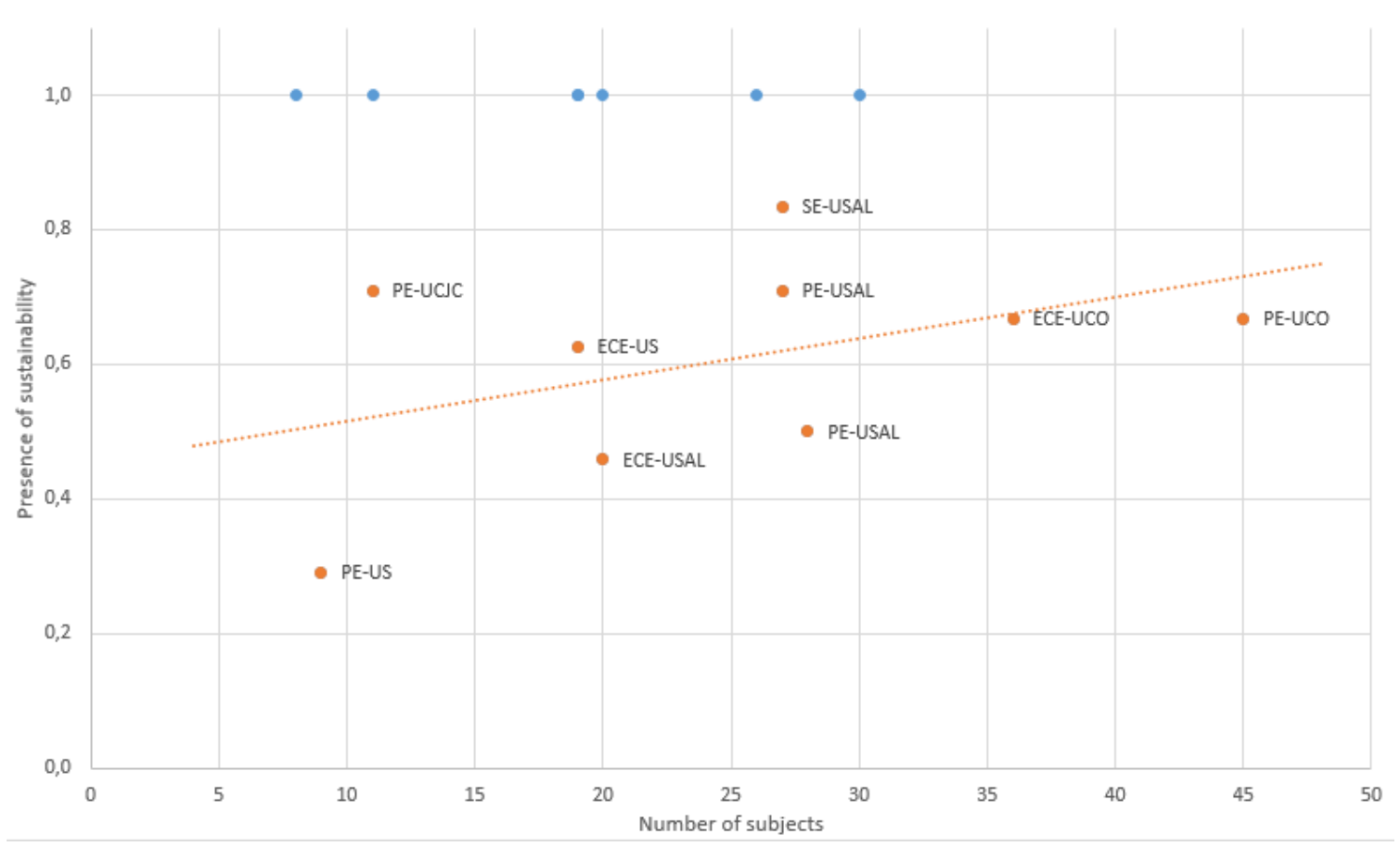

Figure 8. Correlation between the variables "number of subjects that develop sustainability' and 'presence of sustainability' in Higher Education Degrees

\section{Discussion}

The first research question addressed in this work is as follows: To what extent do the analyzed Degrees consider the competencies in sustainability established by the CRUE? All the Degrees have a specific profile of competencies in sustainability, as shown in Table 2. The answer to the other two questions allows us to deepen this profile. We will also use Table 2 to answer the second question: What competencies are more present (strengths) and less present (weaknesses) in the Degrees? The column on the right (Comp.) shows that the least present competency is SUS2 (sustainable use of resources), since $35.42 \%$ of the cells containing LOs are not developed in any subject of some Degree. On the other hand, the competencies with greater presence are SUS4 (application of ethical principles), in which only $15.63 \%$ of the cells are not developed in any subject, and SUS1 (critical contextualization of knowledge), where this 
percentage is $16.67 \%$. For SUS3 (participation in community processes), the percentage is $20.83 \%$. Therefore, we can conclude that the most instrumental competency is that which has less presence in the Higher Education Degrees studied.

The introduction of the ethical principle in Higher Education Degree programs has been and continues to be a reference in the learning processes (SUS4 is the competency with greater presence in the Degrees analyzed). Values education and civic education have a long tradition in Higher Education Degrees (Naval et al. 2011). Both the universities as an institution and the faculties are aware that they must work to promote civic education, recognize the value of each person, seek harmony with the surrounding environment, and show respect for fundamental rights. On the other hand, the management of resources from the perspective of sustainability (SUS2) is an issue that has been introduced more recently into Higher Education Degree programs. The culture of social and environmental responsibility arouses a certain distrust in some university teachers. The introduction of instrumental actions in favor of a sustainable management of resources does not have the same depth as the critical construction of knowledge (Standish 2017).

Table 2 shows that a certain homogeneity exists in the presence of CUs in the Degrees analyzed (column CU). The presence of LOs is similar among the six CUs, showing a percentage difference of approximately $6 \%$, with the exception of CU2.1 (designs and develops actions to improve sustainability). The CU2.1 presents a $35.42 \%$ non-presence, while the rest of CU oscillates between $14.58 \%$ and $20.83 \%$. The CU with the lowest non-presence rate is the CU4.1 (it is coherent in its actions), since only $14.58 \%$ of the LOs are not developed in any of the subjects. Traditionally, students in Higher Education Degree programs have shown great applicability of ethical principles in the implementation of their learning processes (Caro, Ahedo, and Esteban 2018). 
This result suggests that, although Higher Education Degrees have a high number of subjects that imply these principles, this process has little relation with processes that promote sustainability. This represents a challenge and an opportunity: to redesign the social variable of learning with the aim of increasing student participation in processes that promote sustainability.

The number of different subjects in which sustainability is developed in each Degree is significant. In some cases, such as the UCO, a large number of subjects develop sustainability (36 in the ECE Degree, and 45 in the PE Degree), while other Degrees have a smaller number ( 8 in the case of the ECE Degree of the UAM or 9 in the PE Degree of the US). Figure 1 shows that, on average, Degrees include between 19 and 27 subjects that develop competencies in sustainability. The global average is 22.63 subjects per Degree, with a standard deviation of 3.35. When the data are analyzed according to universities, the results are much more variable, as shown in Figure 2. In this case, the average of subjects per university/Degree is 21.57 , similar to the average per Degree, but with a standard deviation of 10.56 . From these data, it is clear that each university uses its own criteria to determine how many subjects develop sustainability. For example, the UCO states that practically all the subjects in the curriculum participate in the development of sustainability. In the current context of the university, it is difficult to believe that the acquisition by students of competences in sustainability is a motivation shared by all the professors who teach at the UCO (in the degrees analyzed), although the teaching guides of the subjects and the official documents of the Degrees $\left(\right.$ Verifica $\left.^{4}\right)$ indicate that they are. This is probably because the team that originally designed the UCO Degree curriculum was itself motivated, or had an explicit directive from the university to include sustainability in all the subjects. Universities

\footnotetext{
${ }^{4}$ All degrees in Spain are subject to a verification process before being authorized. The documentation corresponding to this process is presented in a document called "Verifica" through a software application with the same name.
} 
such as the UAM and the US (13 subjects on average) or the UCJC (11) are at the other extreme. This number of subjects seems more realistic and probably corresponds to subjects taught by motivated teachers.

The third research question is as follows: Are there differences in the presence of sustainability competencies in the different Degree programs? We will focus our analysis on the ECE and PE Degrees, which are the Degrees for which we have significant results. Figure 3 shows that SUS1 and SUS4 have the greatest presence in the ECE Degree (more than 85\%), and in the PE Degree (approximately $80 \%$ ). SUS3 is present at almost $80 \%$ in the ECE Degree and just over $70 \%$ in the PE Degree. SUS2 is the one with less presence, and shows a percentage slightly higher than $60 \%$ in both Degrees.

These results raise the following question: Can the presence of competencies in sustainability be determined by the nature and objectives of each Degree? In our opinion, the answer is in the affirmative. Issues such as the generation of waste in everyday life, the types of pollution that affect the environment, the globalized systems that cause climate change, etc., are transmitted more effectively with verbal language mediated by the word (Mindt and Rieckmann 2017). However, the objective of the ECE Degree is to train professionals to work with children whose verbal language is still to be fully developed. The formative nature of the Degree is therefore more aligned with other educational languages related to fields such as iconic, gestural, pictorial and dramaturgical languages, etc., which facilitate a greater presence of sustainability in their development (Botella, Fosati, and Canet 2017). These languages are precisely those most commonly used in the stage of Early Childhood Education. The ECE Degree curricula and the nature of their subjects must therefore be defined to be in tune with the other types of language that teachers will use in their classrooms, and which go beyond 
the interpersonal language mediated by the word. Perhaps this justifies the low presence of SUS2 (Sustainable use of resources and prevention of negative impacts in the natural and social environment) in comparison with the other competencies.

Figure 4 shows two significant aspects. On the one hand, the existence of three universities, the UAM, UCA and UIC, in which the four competencies are $100 \%$ present; on the other hand, the lack of presence of SUS2 and SUS3 in the USAL. SUS2 is again the competency showing the lowest presence, with a figure of only $35 \%$ in the UCO and the US, and $0 \%$ in the USAL. Therefore, a homogeneous presence of the competencies according to universities does not exist. If this presence is analyzed in the PE Degree (see Figure 5), the results show that once again the UAM, the UCA and the UIC maintain a $100 \%$ presence in the four competencies, while SUS3 is not developed in the USAL, and SUS2 is not developed in the US. The results show a disparity in the presence of competencies according to universities. It is significant that in the ECE Degree (Figure 4), four of six universities studied indicate a 100\% presence of SUS3 and SUS4. In the PE Degree (Figure 5), four of seven universities indicate a $100 \%$ presence of SUS1, SUS3 and SUS4.

Figure 6 shows the data for figures 4 and 5, together in a single graph, which enables the global presence of sustainability in each university and Degree to be analyzed. Three universities (the UAM, UCA, and UIC) declare a $100 \%$ presence of sustainability in both the ECE and the PE Degrees. The UCO indicates a presence of 65\% in both Degrees. The US develops sustainability more in the ECE Degree (62\%) than in the PE Degree (29\%), in which it only develops three of the four competencies (SUS2 is not developed). The USAL develops sustainability at approximately $50 \%$ in both Degrees, although the ECE Degree develops neither SUS2 nor SUS3, and the PE 
Degree does not develop SUS3. Finally, the UCJC develops sustainability in the PE Degree to $70 \%$.

Given the homogeneity of the treatment of sustainability in ECE and PE Degrees, these results pose a new question: Is there a correlation between the presence of competencies in sustainability in the curricula and the existence of sustainability policies in the universities? The oldest universities, the US and the USAL, have the least presence of sustainability, which leads us to a second question: Why do universities with more years of existence, such as the USAL (801 years) or the US (514 years) have a lower presence of sustainability in their Higher Education Degree programs? To what extent does the weight of history make it difficult to introduce topics that, until recently, were not relevant to university policies?

With respect to the presence of the four competencies in sustainability in each of the domain levels of the taxonomy, Figure 7 shows that the presence of LOs in the 'Know' domain level is greater than in the rest of the levels for SUS1 (more than $90 \%$ presence), SUS2 (80\% presence), and SUS3 (85\% presence). In these three competencies, the domain level 'Know How' is also more present than the 'Demonstrate + Do' level. We may therefore conclude that in SUS1, SUS2 and SUS3, the development of the lower domain levels is enhanced. The SUS4 competency, on the other hand, has a similar presence in the three domain levels, and even the highest level of the taxonomy is the one with the most presence (88\%). In general terms, these results show the priority given in the higher education system to the development of conceptual and cognitive competencies, as opposed to the attitudinal and procedural ones.

These results provide grounds for recommending a greater balance in the design of the curricula in the higher education system, with the aim of achieving a greater presence of attitudinal and ethical competencies, as proposed by other research (Murga- 
Menoyo 2015). Human beings cannot live without reacting to their environment and to world-wide problems, and should not do so only from an intellectual conception, but also from the attitudes and behaviors they may adopt. The traditional role of universities has been simply the transmission of knowledge, with the subsequent emergence of the obligation to conduct research, and more recently to acquire knowledge that is transferable to real-world issues.

Finally, we have studied the possible correlation between the number of subjects that develop sustainability and the presence of sustainability in Higher Education Degree programs. When all the data are considered, no such correlation is found, although a correlation does appear when the Degrees that have a $100 \%$ presence of the four competencies in sustainability are eliminated (Figure 8). This suggests that the universities that state that they develop $100 \%$ sustainability may do so as a result of university policy. In other words, the university has decided to develop sustainability in all the curricula, and the competencies in sustainability (all) in the Degrees are assigned to a set of subjects. These subjects oscillate between all the subjects of the Degree (probably also due to university policy issues) to a few subjects, which are surely those taught by teachers who are really motivated by sustainability.

The correlation that appears when outliers are eliminated suggests that, in general, the presence of sustainability in the Degrees increases with the number of subjects in which it is implemented. This is a reasonable result, but it also shows that no defined strategy for working on sustainability exists in the Degrees. If this strategy existed, the four competencies in sustainability would be distributed among the subjects of the sustainability itinerary, independently of this number, in order to implement the four competencies in sustainability at $100 \%$. This strategy may exist in the Degree programs that where it is stated that the four competencies are implemented $100 \%$. In 
this case, Figure 8 shows the Degrees/universities that follow a strategy for developing sustainability (presence $=1$ ) and those that have no predefined strategy and leave the development of sustainability in the hands of their teachers.

This is an exploratory study that is subject to several limitations. First, it is restricted to the 16 Degrees under study. The data cannot be extrapolated to all Higher Education Degrees in the Spanish university system, but they do enable us to infer to what extent sustainability is present in these Degrees. Second, this is a quantitative analysis that only measures the presence of sustainability in the curricula. Therefore, the way in which sustainability is developed, the number of hours dedicated to it and the activities carried out, etc., are not analyzed. Finally, data have been mainly extracted from the teaching guides of the subjects and from the Verifica document of each Degree. It may be that the subjects are not fully or faithfully reflected in these documents, and that they do not completely correspond to all the details therein.

\section{Conclusions}

This research aims to answer three questions: (Q1) - To what extent do the Degrees analyzed consider the competencies in sustainability established by the CRUE? (Q2) What competencies are more present (strengths) and less present (weaknesses) in the Degrees?, and (Q3) - Are there differences in the presence of sustainability competencies in the different Degree programs? The investigation is of an exploratory type in which a quantitative analysis is conducted. For this reason, the data do not allow causal explanations to be established, but only the identification of situations.

The findings of this work indicate that much remains to be done in the academic field to fully incorporate sustainability into higher education. With respect to question Q1 (To what extent do the Degrees analyzed consider the competencies in sustainability 
established by the CRUE?), significant differences are observed in the number of subjects that each university/Degree devotes to developing sustainability: a very small number in some, and practically all in others. Most Degrees develop sustainability by placing more emphasis on one competency more than another, depending on the university and Degree. Thus, each Degree has its own sustainability profile, which provides the answer to question Q3 (Are there differences in the presence of sustainability competencies in the different Degree programs?). In general, the highest levels of the taxonomy (Know How and Demonstrate + Do) are the least developed, which indicates that the development of sustainability is quite superficial. The data show that no common framework exists, despite the fact that the CRUE has been promoting the implementation of competencies in sustainability for the entire Spanish university system since 2005 .

Regarding question Q2 (What competencies are more present (strengths) and less present (weaknesses) in the Degrees?), we find that SUS2 (sustainable use of resources) is the least present competency. We believe that this is because the sustainable use of resources is a recent problem due to the challenges facing society today, which was not a priority in the university system until the CRUE started working on this line in 2005. The university has always been a promoter of social and educational innovation, making it a leader in learning processes based on ethical criteria. This fact is reflected in this study, since SUS4 (related to the values of sustainability in personal and professional behavior) is the competency that has more presence in the Degrees analyzed. On the other hand, $90 \%$ of the Degrees studied develop SUS1 (critical contextualization of knowledge establishing interrelations with social, economic and environmental, local and/or global problems). 
We believe that, in their commitment to social reality, universities must address the social and environmental challenges that guarantee the quality of life of all people. To this end, and especially in Higher Education Degree programs, universities should encourage the creation of networks and the development of research projects that transfer representative data, and above all the training of students competent in sustainability.

The competencies that the CRUE ratified in 2012 have already had effects on the university curriculum, at least in the lower domain levels. Higher Education Degrees have a high number of subjects that involve student participation and critical attitude. However, these subjects fail to develop processes that promote sustainability.

The most developed competency unit is that which fosters participation in community processes for promoting sustainability. The participation of students in transformative processes is facilitated and encouraged from Higher Education Degrees, but development of the highest domain level of the taxonomy remains a subject that needs to be addressed. This involves the application and transfer of learning to real and everyday professional situations, which probably has to do with connecting level L1 learning outcomes with level L3, or what is sometimes referred to as educating for life, which is included as a proposal in integrated curriculum design, where procedures, values, attitudes, and the emotional dimension have more presence in the learning process.

We believe that the challenge is to redesign goals and learning processes that address the construction of a university curriculum for inclusion, equality, diversity, social entrepreneurship, networking, technical and creative skills for a decent job. All these aspects are included in the SDG (UNESCO 2017). 
While in this work a quantitative analysis is carried out, it is also necessary to conduct a qualitative analysis to determine how sustainability is being developed in the Spanish university system. This paper shows what competencies are developed in each Degree and at what domain level, but not how they are developed. The acquisition of this information is essential in order to build up a complete picture of the current state of sustainability learning. Objective 4 of the EDINSOST project is devoted to work in this line, and we hope to publish the results soon to complement those presented in this work.

\section{References}

Albareda-Tiana, S.; Ruíz-Morales, J.; Azcárate, P.; Valderrama_Hernández, R.; Múñoz, J.-M. The EDINSOST Project: Implementing the Sustainable Development Goals at University level. In Universities as Living Labs for Sustainable Development: Supporting the Implementation of the Sustainable Development Goals; Leal Filho, W., Salvia, A.L., Pretorius, R., Brandli, L., Manolas, E., Alves, M.F.P., Azeiteiro, U., Rogers, J., Shiel, C., Paço, A., Eds.; Springer: Berlin, Germany, 2019.

Botella, A. M'. Fosati, A., and Canet, R. 2017. "Emotional and creative development in early childhood education though the visual arts and music." Creativity and Educational Innovation Review (CEIR) 1: 70-86. doi: 10.7203/CREATIVITY.1.12063

Caro, Ma . C., Ahedo, J., and Esteban, F. 2018. "Kohlberg's moral education proposal and its legacy at university: present and future.” Revista española de pedagogía 76 (269): 85-100. doi: 10.22550/REP76-1-2018-04.

Cotton, D., Bailey, I., Warren, M., and Bissell, S. 2009. "Revolutions and second $\square$ best solutions: Education for Sustainable Development in Higher Education." Studies in Higher Education 34 (7): 719-733. doi: 10.1080/03075070802641552\#.VBGR25RdWmE.

CRUE 2012. "Directrices para la introducción de la Sostenibilidad en el Curriculum." Accessed 13 november 2018. http://www.crue.org/Sostenibilidad/CADEP/Documents/DIRECTRICES\%20SOSTENIBI LIDAD\%20CRUE\%202012.pdf. 
Miller, G. E. 1990. "The assessment of clinical skills/competence/performance." Academic medicine 65 (9): S63-S67.

Mindt, L., and Rieckman, M. 2017. "Developing competencies for sustainability-driven entrepreneurship in higher education: a literature review of teaching and learning methods." Teoría de la Educación. Revista Interuniversitaria 29 (1): 129-159. doi:10.14201/teoredu2017291129159

Murga-Menoyo, Ma . A. 2015. "Competencies for sustainable development: capabilities, attitudes and values purpose of education in the framework of the post-2015 global agenda." Foro de Educación 13 (19): 55-83. doi: 0.14516/fde.2015.013.019.004

Naval, C., García, R., Puig, J., and Santos, M. A. 2011. "Ethical and civic education and the social commitment of university students." Encounters on education 12: 77-91. doi: 10.15572/ENCO2011.05

Shephard, K., and Furnari, M. 2013. "Exploring what university teachers think about education for sustainability." Studies in Higher Education 38 (10): 1577-1590. doi: 10.1080/03075079.2011.644784.

Sales de Aguiar, T. R. and Paterson, A. S. 2018. "Sustainability on campus: knowledge creation through social and environmental reporting." Studies in Higher Education 43 (11): 18821894. doi: 10.1080/03075079.2017.1289506.

Sánchez-Carracedo, F., Segalàs, J., Vidal, E., Martín, C., Climent, J., López, D. and Cabré, J., 2018. "Improving Engineering Educators Sustainability Competencies by using Competency Maps. The EDINSOST Project." International Journal of Engineering Education 34 (5): 1527-1537.

Segalàs, J., Sánchez-Carracedo, F., Hernández, A., Busquets, P., Tejedor, G. and Horta, R. 2018. "The EDINSOST Project. Training sustainability change agents in Spanish and Catalan engineering Education." Paper presented at the 9th International Conference on Engineering Education for Sustainable Development Conference 2018, New Jersey, June 109-116.

Standish, P. 2016. "The Disenchantment of Education and the Re-enchantment of the World." Journal of Philosophy of Education 50 (1): 98-116. doi: 10.1111/1467-9752.12176.

UNESCO 2017. "Education for Sustainable Development Goals. Learning Objectives." Accessed 10 december 2018. http://unesdoc.unesco.org/images/0024/002474/247444e.pdf 



\section{Glossary}

CRUE: Council of Presidents of the Spanish Universities

CU: Competency Unit

EDINSOST: Education and social innovation for sustainability.

ECE: Bachelor Degree in Early Childhood Education

L1: Level 1 of taxonomy: Know

L2: Level 2 of taxonomy: Know how

L3: Level 3 of taxonomy: Demonstrate + Do

LO: Learning Outcome

PE: Bachelor Degree in Primary Education

P: Bachelor Degree in Pedagogy

SDG: Sustainable Development Goals

SE: Bachelor Degree in Social Education

SUS1: Sustainability competency 1: Critical contextualization of knowledge by establishing interrelations with social, economic, environmental, local and/or global problems.

SUS2: Sustainability competency 2: Sustainable use of resources and prevention of negative impacts on the natural and social environment.

SUS3: Sustainability competency 3: Participation in community processes that promote sustainability.

SUS4: Sustainability competency 4: Application of ethical principles related to the values of sustainability in personal and professional behavior.

UAM: Autonomous University of Madrid

UCA: University of Cádiz

UCO: University of Córdoba 
UCJC: Camilo José Cela University

UNESCO: United Nations Educational, Scientific and Cultural Organization

UIC: International University of Catalonia

USAL: University of Salamanca

US: University of Seville 


\section{Appendix 1}

Table 3. Sustainability Competency Map for Higher Education Degrees, as presented in Albareda-Tiana et al. (2019).

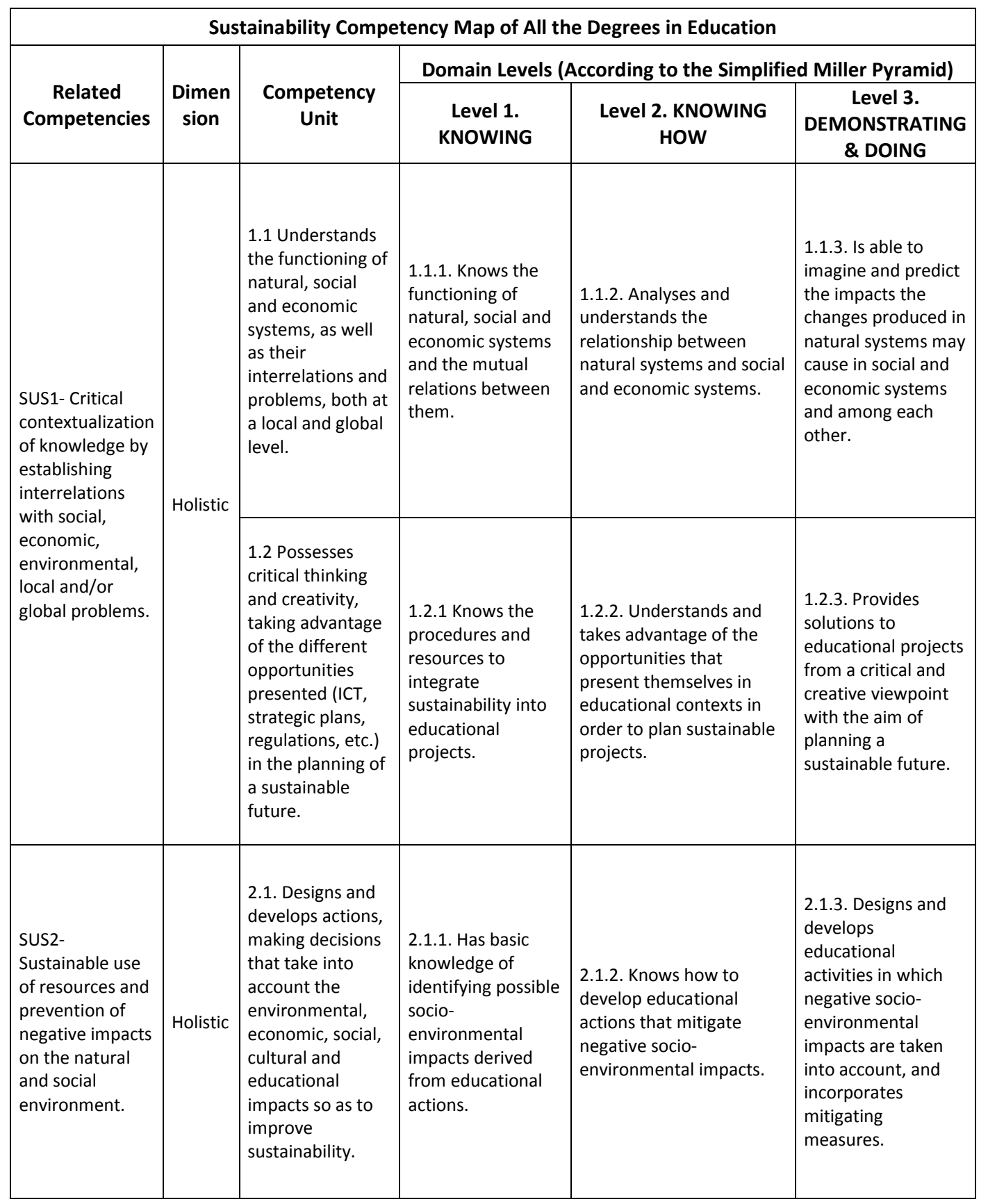




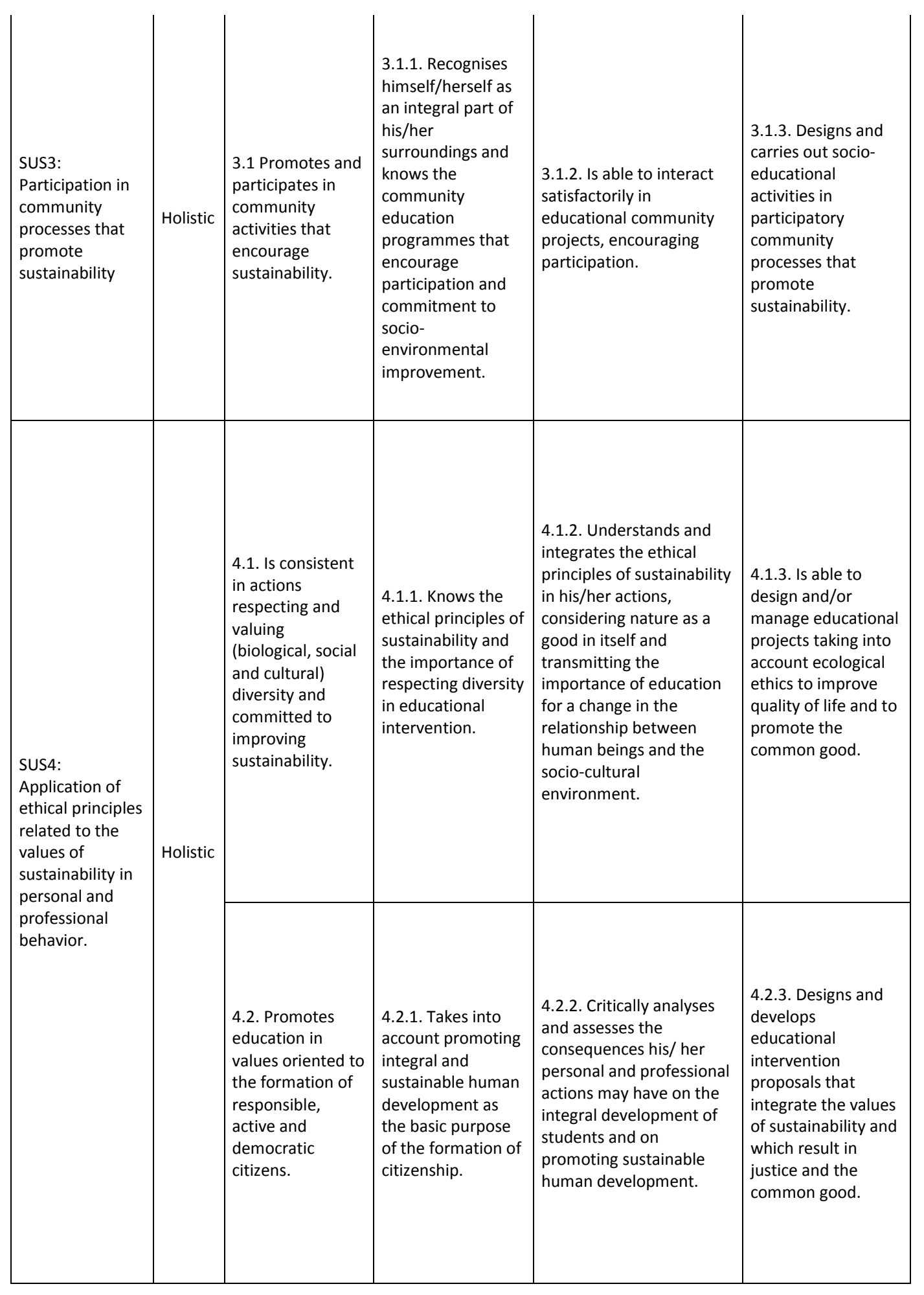

Funding details: This work was supported by the Spanish Ministry of Economy, Industry and Competitiveness under Grant EDU2015-65574-R.

Disclosure statement. No potential conflict of interest was reported by the authors. 


\section{Acknowledgments}

We wish to thank the rest of the EDINSOST team for their collaboration in this work, especially Francisco Moreno, Bárbara Sureda, Miguel Antúnez and Ibon Gutiérrez.

\section{Declaration of interest statement}

None

\section{Biographical note.}

Fermín Sánchez-Carracedo. Bachelor Degree in Informatics (1987) and $\mathrm{PhD}$ in Informatics (1996). Associate Professor in the Department of Computer Architecture, UPC-BarcelonaTech, since 1997. His research areas are teaching innovation and education for sustainability. Member of the BCN-SEER, group (https://bcnseer.upc.edu/en) which coordinates the track 'Education for Sustainable Development in Engineering'. Main researcher of the EDINSOST project. Teacher of the Postgraduate Program 'University Teaching in Science, Technology, Engineering and Mathematics (STEM)' of the UPC-BarcelonaTech since 2017 and teacher of the Master Degree in 'Innovative Learning Processes' of the Universidad de Guadalajara (Mexico) since 2017. He was a course instructor at the UOC (1997-2010) and Vice-Dean of Innovation at the Barcelona School of Informatics-FIB (2007 -2013). Since July 2013, he has been Deputy of Innovation at the FIB. He has won several awards: the 1st European award for best practices for the integration of Sustainable Human Development (SHD) into technology and engineering education (2013), awarded to the STEP team; the design for recycling award, modality Strategies, (Mention), awarded by the Generalitat de Catalunya to the UPC-Reutilitza project (2014); eight best papers in JENUI conference since 2003; and the AENUI Prize for Innovation and Teaching Quality 2017, awarded by AENUI.

Jorge Ruiz-Morales. Bachelor of Education Sciences (Pedagogy) and Doctor by the University of Seville (Spain). Professor at the University of Seville and International University of La Rioja. He works in the following lines of research: environmental education, teaching innovation, citizen participation, inclusion, and sustainability. He has developed his professional activity linked to environmental education, citizen participation, training of trainers and university teaching. He has received two important awards related to citizen participation and sustainability in local development, the first as part of the Participatory Budgeting process of the city of Seville, within the framework of the research project agreed between the University of Seville and the Hon. Seville City Council (year 2006), being coordinator of Laboraforo Team, belonging to GIEPAD; the second by the Almensilla Project (Con) Suma Responsabilidad, awarded by the FAMP and the Ministry of the Environment (Junta de Andalucía), in 2014, for the work carried out together with the Hon. City council of Almensilla.

Rocío Valderrama Hernández. Teaching Assistant Doctor, contracted to the University of Seville. Member of the research group HUM596, Director of the 
Cooperation Group Adult Education and Human Development PANGEA, Member of the Gender and Cooperation Research Network. Doctor in Pedagogy from the University of Seville. Her line of research concerns human development, social and environmental education, participatory research and the construction of citizenship from the earliest educational levels. Teacher (2016 to present) in the course of Expert in Educating Emotions: Emotional Intelligence, Social Skills and Mediation at the University of Seville. Teacher from the 2011/2012 academic year to the present in the Andalusian Interuniversity Master of Environmental Educators, awarded in 2014 as the best educational space for environmental practices by the Regional Government of Andalusia. Teacher from the 2009/2010 academic year to the present in the Master's Degree in Compulsory Secondary Education and Baccalaureate, Vocational Training and Language Teaching. Module Society, family and education and educational processes and contexts. Teacher (2011/2012) in University Master's Degree in Gender and Cooperation at the University of Seville.

José Manuel Muñoz Rodríguez. Professor of the Theory of Education and Environmental Pedagogy University, since January 2012, in the Department of Theory and History of Education. He holds a Degree (1998) and a PhD in Pedagogy (2004), with an Extraordinary Doctorate Award, at the University of Salamanca. His research focuses on Environmental Pedagogy for sustainable development and curricular sustainability. Main researcher of the Recognized Research Group of the University of Salamanca: 'Processes, spaces and educational practices'. He is a member of different international teaching and research networks -CIREMIA (Inter-University Network of Recherche sur l'Education et la culture dans le Monde Ibérique et ibéro-Américain), EERA (European Educational Research Association), WERA (World Education Research Association), SEP (Spanish Society of Pedagogy) and member of the group 'Sustainability-CRUE'. Associate Editor of the 'Theory of Education Magazine. Interuniversity Magazine '. He was Secretary of the Department of Theory and History of Education (2008-2014), where he currently holds the position of Deputy Director. He has also been Academic Director of the Interuniversity Program of Experience at the University of Salamanca (2014-2017) and Secretary of the Board of Directors of AEPUM - State Association of University Programs for the Elderly - (2016-2018).

Antonio Gomera Martínez. Bachelor of Environmental Sciences (2001) and Doctor of Environmental Education (2011) by the University of Córdoba. Accredited as Assistant Professor Doctor (2017). Coordinator of the Environmental Protection Service of the University of Córdoba (since 2001). Coordinator and Secretary of the Sustainability Classroom of the University of Córdoba (since 2008). Collaborator in Degree and Master's teaching on environmental education since 2007. His research line focuses on the study of environmental awareness and pro-environmental behavior in the university environment, linked to the processes of curriculum sustainability. He has several publications and communications in the national and international fields. Member of the Research Group SEJ049 'Educational evaluation and innovation'. He has extensive experience in training and environmental awareness actions for groups of all types (students, faculty, administration and services personnel, companies, citizens, etc.). Member of the Sectorial Commission of CRUE-Sustainability, within the Working Group 'Curriculum Sustainability'. 